Original papers

\title{
Dynamic assessment of forest resources quality at the provincial level using AHP and cluster analysis
}

\author{
Jiguang Feng ${ }^{\mathrm{a}}$, Jingsheng Wang ${ }^{\mathrm{b}, *}$, Shuaichen Yao ${ }^{\mathrm{a}}$, Lubin Ding ${ }^{\mathrm{a}}$ \\ ${ }^{a}$ School of Environment and Natural Resources, Renmin University of China, Beijing 100872, China \\ ${ }^{\mathrm{b}}$ Lhasa Plateau Ecosystem Research Station, Key Laboratory of Ecosystem Network Observation and Modeling, Institute of Geographic Sciences and Natural Resources \\ Research, Chinese Academy of Sciences, Beijing 100101, China
}

\section{A R T I C L E I N F O}

\section{Article history:}

Received 2 December 2015

Received in revised form 18 March 2016

Accepted 11 April 2016

Available online 18 April 2016

\section{Keywords:}

Forest resources quality

Analytic hierarchy process

Hierarchical cluster analysis

Forest management

National Forest Inventory

China

\begin{abstract}
A B S T R A C T
The aim of this study was to quantitatively assess and analyze the dynamic changes and current problems of Chinese forest resources based on the National Forest Inventory (NFI). In this study, a hierarchical model was established using the analytic hierarchy process to assess forest resources quality (FRQ) at the provincial level. Four criteria were used, including forest quantity, forest productivity, forest structure, and forest health and each criterion was further composed of multiple factors. Among these assessment factors, stock volume per unit area was the most important, while canopy structure was the least important. The ranges of FRQ Indies across China during the 6th NFI (1999-2003), 7th NFI (2004-2008), and 8th NFI (2009-2013) were 0.3031-0.6366, 0.3499-0.7186, and 0.3534-0.7555, respectively. From the 6 th to 8 th NFI, forest quality improved by different degrees for all provinces, whereas the other three criteria presented an increasing or decreasing trend. In general, the implementation of ecological projects has significantly improved the FRQ at provincial and national levels. During the 8th NFI, the FRQ levels were excellent for 3 provinces, good for 15 provinces, medium for 12 provinces, and only one province exhibited an inferior level of FRQ. Based on cluster analysis, Chinese forest resources during the 8th NFI could be grouped into four clusters according to the provincial administrative region, and each cluster had its own advantages and disadvantages. Stock volume increment and forest calamity were in a very good state, while canopy structure was the key factor limiting the FQR for all the clusters. Some relevant measures were proposed to improve the existing conditions of Chinese forest resources. The results of this study are significant in that they can provide theoretical and technical references for future adjustment and sustainable management of forest resources in China.
\end{abstract}

(c) 2016 Elsevier B.V. All rights reserved.

\section{Introduction}

As the main body of terrestrial ecosystem on earth, forests provide fundamental services for human (Nunez et al., 2006), including the provision of timber and other forest products, soil and water conservation, nutrient accumulation, and atmosphere environmental purification (Costanza et al., 1997; SFA, 2008). Forests are the basis of subsistence and development for human beings and other organisms (Li and Li, 1996) and play an important role in maintaining the global carbon balance, tackling climate change, and protecting biological diversity (Achard et al., 2002). With the continued scarcity of global natural resources and the deterioration of the ecological environment, forests have become the core and

\footnotetext{
* Corresponding author.

E-mail addresses: fjg@ruc.edu.cn (J. Feng), wangjsh@igsnrr.ac.cn (J. Wang), yaoshuaichen@yeah.net (S. Yao), 813665458@qq.com (L. Ding).
}

focus of environmental protection and social development in the world (RGFSD, 2003; Amsallem et al., 2003). To protect forests and forest resources, improve the ecological environment, and promote the sustainable development of society and economics, the Natural Forest Protection Project, the Three-North Forest Protection Project, and the Conversion of Cropland to Forest Project, have been implemented by Chinese government. It is vital to make a comprehensive, objective, accurate, and proper analysis and assessment of the effects of these projects and the status of forest resources quality (FRQ) and the trend in its growth or decline at the provincial as well as the national level. These feedings will then play an important role in providing a scientific basis for the government to develop forestry policies and in macroscopic decision-making (Dang et al., 2008; Zhang et al., 2011).

As a concept, forest quality was first proposed by Stolton in 1992, and then was further developed by Stolton and Dudley in a 
project for the World Wildlife Fund for Nature (WWF) (Dudley et al., 2006). Ever since, the concept has evinced increasing importance and applications in forest conservation and resource management (Haefele et al., 1992; Dudley et al., 2006). FRQ is very similar to forest quality, but differences exist between them. According to previous studies, the definition of FRQ broadly considers two main aspects (Shi and Wang, 2007; Dang et al., 2008; Wu and Zhao, 2011): (i) the material basis of forest resources, (ii) the service function of forest resources (e.g. ecological, social, and economic function). Compared with forest quality, FRQ is more suitable for assessments at a large scale, such as at a landscape, provincial, and national scale. According to our research practice, we used the concept of FRQ in this study. There is no defined or agreed standard concerning the criteria to be taken into consideration when assessing FRQ (Zhang et al., 2011), and the criteria used in relevant studies are usually those that are accessible. In general, in such studies, factors that reflect the intrinsic properties of forests are widely used, e.g. forest naturalness, forest quantity, forest productivity, forest structure, forest health, and forest distribution (Dang et al., 2008; Guo et al., 2010; Wang and Bao, 2011; Wu and Zhao, 2011; Zhang et al., 2011; Riedler et al., 2015). As mentioned previously, to assess the FRQ of a city or province, many criteria need to be considered as a whole. However, not all criteria affecting FRQ are equally significant, which makes the assessment of FRQ complicated, despite the fact that various methods have been used to determine the weights of these criteria. In recent studies on FRQ assessment, the methods used to determine the weights of different criteria have mainly involved the analytic hierarchy process (AHP) (Wang and Bao, 2011; Wang et al., 2013; Yang et al., 2015), factor analysis (Mo et al., 2015), and the Matter-Element Model (Chen et al., 2011; Wu and Zhao, 2011). However, few studies have assessed and analyzed FRQ and its dynamic changes using the integrated approach of AHP and cluster analysis (CA), which can not only be used to assess FRQ but can also be used to determine and analyze problems existing within the same cluster of forest resources.

The aim of the present study was to assess the FRQ at the provincial level during 1999-2003, 2004-2008 and 2009-2013, and then analyze their dynamic changes following the implementation of the three ecological projects in China. The aim, ultimately, was to ascertain similar problems in the same cluster of forest resources during 2009-2013 based on CA, and thus to propose the measures that should be taken in the future management of forest resources, so as to provide theoretical support for relevant departments to make decisions regarding the sustainable development of forests in China.

\section{Materials and methods}

\subsection{Factors used in the assessment of forest resources quality}

In this study, a multi-criteria evaluation process was employed to assess the FRQ at the provincial level. Based on previous studies (Dang et al., 2008; Wang and Bao, 2011; Zhang et al., 2011; Yang et al., 2015), the following criteria were chosen: forest coverage rate, forestry land utilization rate, stock volume per unit area, stock quality, stock volume increment, stand origin structure, forest category structure, tree species structure, age group structure, canopy structure, forest viability, and forest calamity. There were three main reasons for using these factors in this study. First, these factors are adequate for assessing the FRQ at the provincial level. Second, the selection of factors needs to follow certain principles, e.g. feasibility, relative independence, comparability, generality, and representativeness (Dang et al., 2008; Wu, 2010; Zhang et al., 2011). Third, the data relating to the factors used can be recalculated using the original data set provided by relevant institutions and departments.

\subsubsection{Forest coverage rate}

Forest coverage rate is a comprehensive indicator reflecting the abundance, status and extent of forest resources, forestry development and forest benefits within a country or a region (RGFSD, 2003). It is also one of the most important measures for formulating forest management policy, development, and utilization.

\subsubsection{Forest land utilization rate}

Forest land utilization rate reflects the utilization level of land used for forestry. We used the ratio of forested land area and the area of land used for forestry to represent this factor (Table 1). Forested land refers to forestland growing forest vegetation spanning more than $0.0667 \mathrm{hm}^{2}$ with a canopy cover of more than $20 \%$, including arbor forest, economic forest, and bamboo forest (FAO, 2005).

\subsubsection{Stock volume per unit area}

Stock volume per unit area is an important ecological factor that reflects the tree quality at a stand level, and is one of the most important indicators of forest productivity. In forest management, the stock volume per unit area is used mainly for a stand.

\subsubsection{Stock quality}

Growing stock refers to volume over bark of all living trees with a minimum diameter of $10 \mathrm{~cm}$ at breast height (or above buttress if

Table 1

Hierarchical model for the assessment of forest resources quality and calculation methods for various factors.

\begin{tabular}{|c|c|c|c|c|c|}
\hline Objective & Criterion & Factor & Type $^{\mathrm{a}}$ & Unit & Calculation method \\
\hline \multirow{12}{*}{$\begin{array}{l}\text { Forest resources } \\
\text { quality }\end{array}$} & Forest quantity & Forest coverage rate & + & $\%$ & Forest area/total land area \\
\hline & $\begin{array}{l}\text { Forest } \\
\text { productivity }\end{array}$ & $\begin{array}{l}\text { Forestry land utilization } \\
\text { rate }\end{array}$ & + & $\%$ & Forested land area/land area used for forestry \\
\hline & & Stock volume per unit area & + & $\mathrm{m}^{3} \mathrm{hm}^{-2}$ & Using the original data provided by the NFRS \\
\hline & & Stock quality & + & $\%$ & Stock volume of arbor forest/total growing stock volume \\
\hline & & Stock volume increment & + & $\mathrm{m}^{3} \mathrm{hm}^{-2}$ & SVPUAF $^{\mathrm{b}}$ in $n$th NFI - SVPUAF in $(n-1)$ th NFI; $n=6,7,8$ \\
\hline & Forest structure & Stand origin structure & O & $\%$ & Natural forest area/forest area \\
\hline & & Forest category structure & O & $\%$ & Ecological public welfare forest area/forest area \\
\hline & & Tree species structure & O & $\%$ & Broadleaved forest area/arbor forest area \\
\hline & & Age group structure & 0 & $\%$ & Area of young- and middle-aged forest/forest area \\
\hline & & Canopy structure & + & $\%$ & Area of multi-storied stand/stand area \\
\hline & Forest health & Forest viability & + & $\%$ & Area of forest with high viability/forest area \\
\hline & & Forest calamity & - & $\%$ & Area of forest affected by forest diseases and insect pests/forest area \\
\hline
\end{tabular}

\footnotetext{
a + Represents positive-type factor, - represents reversal-type factor, $\bigcirc$ represents extreme value-type factor.
}

b SVPUAF represents the stock volume per unit area of forest. 
these are higher) (FAO, 2005). The growing stock volume includes four categories of volumes for arbor forest, open forestland, scattered trees, and four-side trees. Arbor forest stock volume is an important part of growing stock volume and an important indicator of forest stock quality. So, we used the proportion of stock volume of arbor forest to represent the factor of stock quality (Table 1).

\subsubsection{Stock volume increment}

Stock volume increment refers to the change in stock volume per unit area of forest between two adjacent periods; it is also one of the most important indicators of FRQ and forest productivity. We used stock volume increment per unit area to represent this factor, and the calculation method was listed in Table 1.

\subsubsection{Stand origin structure}

In terms of stand origin, forests can be classified into natural forest and artificial forest. Natural forest is that forest established through natural regeneration manner, whereas artificial forest is that forest of native or introduced species, established through planting, seeding or assisted natural regeneration (FAO, 2005). Compared with artificial forest, the significant characteristics of natural forest are that its forest species are abundant, the ecosystem and forest structure are extremely stable, its resistance to disease and resilience is strong, and it has a high economic value. Therefore, we used the proportion of natural forest to represent the factor of stand origin structure (Table 1).

\subsubsection{Forest category structure}

Forest category structure reflects the rationality of the structure of forest species and is one of the main indicators that can affect the sustainable utilization of forest ( $\mathrm{Wu}, 2010)$. Based on the direction of management and utilization, forests in China are classified into five categories: protection forest, timber forest, economic forest, fuel-wood forest, and special purpose forest (SFA, 2012). These five forests can then be further subdivided into two main types (SFA, 2012): ecological public welfare forest (comprising protection forest and special purpose forest) and commercial forest (comprising the other three categories). Based on the requirements of forest sustainability, the ideal ratio of the two forest types is $1: 1$. We used the proportion of ecological public welfare forest to represent this factor (Table 1 ).

\subsubsection{Tree species structure}

Tree species can be divided into coniferous forest and broadleaved forest. In terms of sustainable utilization of forests, the tree species structure should be reasonable, that is, the ratio of broadleaved forest area to coniferous forest area should be $1: 1$. In this study, we used the proportion of natural forest to represent this factor (Table 1).

\subsubsection{Age group structure}

Based on biological characteristics, the growth process of tree species, and management direction, arbor forest (or stand) can be classified into different age groups. In general, forests are classified into five age groups: young-aged forest, middle-aged forest, nearmature forest, mature forest, and over-mature forest. The age group structure reflects the equilibrium level of stand age composition. According to the theory of the Normal Forest, the ideal ratio of young-aged forest, middle-aged forest, and near-mature/ mature/over-mature forest is 0.33 : $0.34: 0.33$. Only in this way, can forests meet the requirements of sustainable development and utilization. We used the total proportion of young- and middle-aged forest to represent age group structure (Table 1).

\subsubsection{Canopy structure}

In terms of canopy structure, forest can be classified into uniform stand and multi-storied stand. The forest ecosystem with a multi-storied canopy exhibits high productivity, stability and ability to resist interference. We used the proportion of multi-storied stand to represent this factor (Table 1).

\subsubsection{Forest viability}

Forest viability is one of the most important indicators of forest health. The forest with strong viability exhibits a high stability and biological yield, rich biodiversity, strong capacity for tree regeneration, and the ability to resist forest diseases and insect pests. In this study, we used the proportion of forest with strong viability to represent this factor (Table 1 ).

\subsubsection{Forest calamity}

Forest calamity mainly refers to the fact that in a given region, forest internal evolution and external action exceed resistance to natural calamity. This then reduces forest resources, and consequently forestry production suffers serious economic losses (Zhao et al., 2004). Forest calamity is therefore a critical factor affecting forest quality. There are many kinds of forest calamity, including forest diseases (e.g. bacteria, fungi, and viruses) and insect pests, meteorological disasters (e.g. snow, storm, and drought), forest fires and other disasters. Forest diseases and insect pests are the most important factors affecting forest health, so we used the proportion of forest affected by such calamities to represent this factor.

\subsection{Data sources and normalization}

\subsubsection{Data sources}

The data used in this study originated from the National Forest Resources Statistics (NFRS), which presented the findings of the 5th (1994-1998) National Forest Inventory (NFI), 6th NFI (19992003), 7th NFI (2004-2008) and 8th NFI (2009-2013). We obtained the public data set of the 5th, 7th, and 8th NFI from the official website of the State Forestry Administration of the People's Republic of China, and obtained the public data set of the 6th NFI from the official website of the Chinese Forestry Science Data Center (CFSDC). The data of the 5th NFI were provided in the form of the overall state of forest resources (not including the data of forest health, forest structure), and we only used the data to calculate stock volume per unit area of forest in the 5th NFI. The NFRS data sets reflect the actual survey data within the scope of the NFIs, so the national data do not include the regions of Taiwan, Hong Kong, and Macao. In this study, we only analyzed the following 31 provinces: Beijing, Tianjin, Hebei, Shanxi, Inner Mongolia, Liaoning, Jilin, Heilongjiang, Shanghai, Jiangsu, Zhejiang, Anhui, Fujian, Jiangxi, Shandong, Henan, Hubei, Hunan, Guangdong, Guangxi, Hainan, Chongqing, Sichuan, Guizhou, Yunnan, Tibet, Shaanxi, Gansu, Qinghai, Ningxia, and Xinjiang.

\subsubsection{Data normalization}

For the purposes of the database application, the original data were recalculated using various methods (Table 1 ). The recalculated data differed in units and dimensionality, e.g. the unit of stock volume per unit area was measured in $\mathrm{m}^{3} \mathrm{hm}^{-2}$, its range of values was found to be $29.06-268.33$, and the forest coverage rate ranged from $2.90 \%$ to $65.95 \%$. Thus, normalization procedures should be used as part of a comprehensive assessment to convert the various measurement units of the performance ratings into a comparable unit. In this study, we used linear scale transformation of the Max-Min Method to normalize the recalculated data. This method considers both the maximum and minimum performance ratings of factors during calculation, and has the advantage that the 
scale measurement is precisely between 0 and 1 for each factor (Celen, 2014). Moreover, this method was more suited to this study in that negative values may have occurred in the recalculated data, e.g. the factor of stock volume increment. The normalized value can be considered as the score of a factor.

The factors used in this study can be classified into three types: positive-, reversal-, and extreme value-type (the type of each factor was listed in Table 1). For the positive-type factor, the normalized value $S_{i j}$ was obtained using Eq. (1); for the reversal-type factor, the standardized value $S_{i j}$ was obtained using Eq. (2); for the extreme value-type factor, the standardized value $S_{i j}$ was obtained using Eq. (3), as follows:

$$
\begin{aligned}
S_{i j} & =\frac{x_{i j}-\min \left(x_{i j}\right)}{\max \left(x_{i j}\right)-\min \left(x_{i j}\right)} \\
S_{i j} & =\frac{\min \left(x_{i j}\right)-x_{i j}}{\max \left(x_{i j}\right)-\min \left(x_{i j}\right)} \\
S_{i j} & =1-\left|\frac{1-x_{0}}{x_{0}}\right|
\end{aligned}
$$

where $x_{i j}$ is the recalculated data, $S_{i j}$ is the normalized value, max $\left(x_{i j}\right)$ is the maximum value in $x_{i j}, \min \left(x_{i j}\right)$ is the minimum value in $x_{i j}$, and $x_{0}$ is the reference value as described above (for the factors relating to forest category structure, tree species structure, and age group structure, the reference values were $0.50,0.50$, and 0.67 , respectively).

\subsection{Determination of weight by AHP}

The AHP is a multi-criteria decision-making (MCDM) approach introduced by Saaty $(1980,1994)$. It is a flexible and powerful tool for handling both qualitative and quantitative problems (Lee et al., 2014) and is widely used in comprehensive assessments (Akinci et al., 2013; Garcia et al., 2014; Al-Oqla et al., 2015; Zhang et al., 2015; Gong et al., 2015). According to the method developed by Saaty (2008), applying AHP to determine the weight of factors involved four basic steps in this study.

The first step was to construct a hierarchical model consisting of objective, criteria, and factors. In the hierarchical model, the objective was FRQ and the criteria consisted of forest quantity, forest productivity, forest structure, and forest health, each of which had 1-5 concrete factors (Table 1 ).

The second step was to assign the relative importance of factors by creating a pairwise comparison matrix. The judgments in the pairwise comparison matrix were determined by consulting the opinions of experts, in which six scientists with forestry backgrounds were invited to estimate the relative importance of criteria or factors based on Saaty's scale (Table 2). The final judgment matrices for this study were given in Table 3.

The third step was to check the consistency of the judgment matrix. To measure the consistency of pairwise comparison judgments, the consistency ratio (CR) proposed by Saaty (1980) was used. The level of consistency is reasonably acceptable if the CR is less than the upper limit of 0.1 (Saaty, 1980). In this study, the CR was $0.0039,0.0034,0.0474$, and 0.0089 for the matrix FQR, forest productivity, forest structure, and forest health (Table 3), respectively, which indicated that all of the matrices were consistent.

The fourth step was to calculate the weights based on eigenvector values. Based on the pairwise comparison matrix, the contribution weight of each factor toward FRQ can be obtained. The weight of each criterion or factor was computed using the Yet Another AHP 9.0 software (Beijing Xinshengyun Software Company, China) and the results were given in Table 3. For each factor, the higher the weight, the more preferable the factor.

\begin{tabular}{|c|c|c|}
\hline $\begin{array}{l}\text { Intensity of } \\
\text { importance }\end{array}$ & Definition & Explanation \\
\hline 1 & Equal importance & $\begin{array}{l}\text { Two activities contribute equally to } \\
\text { the objective }\end{array}$ \\
\hline 3 & $\begin{array}{l}\text { Weak importance of one } \\
\text { over another }\end{array}$ & $\begin{array}{l}\text { Experience and judgment slightly } \\
\text { favor one activity over another }\end{array}$ \\
\hline 5 & $\begin{array}{l}\text { Essential or strong } \\
\text { importance }\end{array}$ & $\begin{array}{l}\text { Experience and judgment strongly } \\
\text { favor one activity over another }\end{array}$ \\
\hline 7 & $\begin{array}{l}\text { Demonstrated } \\
\text { importance }\end{array}$ & $\begin{array}{l}\text { An activity is strongly favored and } \\
\text { its dominance demonstrated in } \\
\text { practice }\end{array}$ \\
\hline 9 & Absolute importance & $\begin{array}{l}\text { The evidence favoring one activity } \\
\text { over another is of the highest } \\
\text { possible order of affirmation }\end{array}$ \\
\hline $2,4,6,8$ & $\begin{array}{l}\text { Intermediate values } \\
\text { between the two } \\
\text { adjacent judgments }\end{array}$ & When compromise is needed \\
\hline Reciprocals & \multicolumn{2}{|c|}{$\begin{array}{l}\text { If activity } i \text { has one of the above numbers assigned to it when } \\
\text { compared with activity } j \text {, then } j \text { has the reciprocal value when } \\
\text { compared with } i\end{array}$} \\
\hline
\end{tabular}

Table 2

Fundamental scale for pairwise AHP comparisons (Saaty, 1980).

\subsection{Calculation of the forest resources quality index and its grades}

The forest resources quality index (FRQI) was computed in a manner similar to those used in the linear additive combination models (Chen et al., 2011; Wu and Zhao, 2011; Gong et al., 2015), as follows:

$F R Q I=\sum_{i=1}^{n}\left(W_{i} \cdot S_{i}\right)$

where $n$ is the number of factors (Table 1 ) and $W_{i}$ represents the weight of factor $i$, which is computed by using AHP (Table 3), and $S_{i}$ represents the normalized value (or score) of factor $i$. As previously mentioned, both the weights and the normalized values are between 0 and 1 , and the FRQI values are also between 0 and 1 , where a value of 0 represents the worst and 1 indicates the best. The FRQIs of 31 provinces during 6th, 7th, and 8th NFI were calculated using IBM SPSS Statistics 20.0 software (SPSS Inc., USA), and the Kolmogorov-Smirnov test resulted in a $p$-value much greater than 0.05 , indicating a normal distribution. The classification of $F R Q I$ was based on a related study (Mo et al., 2015) and modified slightly in this study. The FRQIs and the scores for forest productivity, forest quantity, forest productivity, and forest structure during the three NFIs were calculated and classified into four grades: excellent $(0.70-1.00)$, good $(0.55-0.70)$, medium $(0.40-0.55)$, and inferior (0.00-0.40) (Table 4).

\subsection{Cluster analysis}

Cluster analysis, also called clustering, is a statistical approach that attempts to find groups of closely related observations so that observations that belong to the same cluster are more similar to each other than observations that belong to other clusters (Bishop, 2006; Petcharat et al., 2012). The ideal number of clusters can be determined graphically by creating a dendrogram, a tree diagram commonly used in CA (Manly, 1994; McKenna, 2003). As a common classification method, CA has long played an important role in a wide variety of fields (Petcharat et al., 2012). In the field of forestry, CA has been applied to the recognition and zoning of forest fire risk (Orozco et al., 2012; Li et al., 2015; Chang et al., 2015), the classification of forest management into subdivisions (Ma et al., 2015), and the classification of forest welfare services (Cha, 2015). In the application of CA, the provinces with similar characteristics of forest resources would be gathered into one cluster, and these characteristics would be significantly different from 
Table 3

Pairwise comparison matrix of objective and criteria.

\begin{tabular}{|c|c|c|c|c|c|c|c|c|c|}
\hline & & A & $\mathrm{B}$ & $\mathrm{C}$ & $\mathrm{D}$ & $\mathrm{E}$ & Priorities & Weight & Consistency $^{\mathrm{a}}$ \\
\hline \multirow[t]{4}{*}{ Forest resources quality } & A. Forest quantity & 1 & $1 / 2$ & $1 / 3$ & 2 & & 0.1810 & & $\lambda_{\max }=4.1191$ \\
\hline & B. Forest productivity & 2 & 1 & 1 & 2 & & 0.3584 & & $C R=0.0446$ \\
\hline & C. Forest structure & 3 & 1 & 1 & 2 & & 0.3199 & & \\
\hline & D. Forest health & $1 / 2$ & $1 / 2$ & $1 / 2$ & 1 & & 0.1407 & & \\
\hline Forest quantity & A. Forest coverage rate & 1 & & & & & 1.0000 & 0.1810 & \\
\hline \multirow[t]{4}{*}{ Forest productivity } & A. Forestry land utilization rate & 1 & $1 / 2$ & 3 & 2 & & 0.2804 & 0.0897 & $\lambda_{\max }=4.0965$ \\
\hline & B. Stock volume per unit area & 2 & 1 & 5 & 2 & & 0.4524 & 0.1447 & $C R=0.0361$ \\
\hline & C. Stock quality & $1 / 3$ & $1 / 5$ & 1 & 1 & & 0.1111 & 0.0356 & \\
\hline & D. Stock volume increment & $1 / 2$ & $1 / 2$ & 1 & 1 & & 0.1561 & 0.0499 & \\
\hline \multirow[t]{5}{*}{ Forest structure } & A. Stand origin structure & 1 & 2 & 3 & 1 & 5 & 0.3277 & 0.1174 & $\lambda_{\max }=5.2173$ \\
\hline & B. Forest category structure & $1 / 2$ & 1 & 2 & $1 / 3$ & 3 & 0.1715 & 0.0615 & $\mathrm{CR}=0.0485$ \\
\hline & C. Tree species structure & $1 / 3$ & $1 / 2$ & 1 & $1 / 3$ & 2 & 0.1095 & 0.0392 & \\
\hline & D. Age group structure & 1 & 3 & 3 & 1 & 2 & 0.3108 & 0.1114 & \\
\hline & E. Canopy structure & $1 / 5$ & $1 / 3$ & $1 / 2$ & $1 / 2$ & 1 & 0.0804 & 0.0288 & \\
\hline \multirow[t]{2}{*}{ Forest health } & A. Forest viability & 1 & 2 & & & & 0.6667 & 0.0938 & $\lambda_{\max }=2.0000$ \\
\hline & B. Forest calamity & $1 / 2$ & 1 & & & & 0.3333 & 0.0469 & $C R=0.0000$ \\
\hline
\end{tabular}

a $\lambda_{\max }$ Represents maximum eigenvalue.

Table 4

Number of provinces classified under the four grades.

\begin{tabular}{|c|c|c|c|c|c|c|c|c|c|c|c|c|c|c|c|c|}
\hline \multirow[t]{2}{*}{ Grade } & \multirow[t]{2}{*}{ Range of scores } & \multicolumn{3}{|c|}{ Forest quantity ${ }^{\mathrm{a}}$} & \multicolumn{3}{|c|}{ Forest productivity } & \multicolumn{3}{|c|}{ Forest structure } & \multicolumn{3}{|c|}{ Forest health } & \multicolumn{3}{|c|}{$\begin{array}{l}\text { Forest resources } \\
\text { quality }\end{array}$} \\
\hline & & A & B & $\mathrm{C}$ & A & B & C & A & B & C & A & B & $\mathrm{C}$ & A & B & $\mathrm{C}$ \\
\hline Excellent & $0.70-1.00$ & 4 & 7 & 8 & 1 & 1 & 1 & 3 & 4 & 3 & 1 & 22 & 24 & 0 & 3 & 3 \\
\hline Good & $0.55-0.70$ & 6 & 3 & 6 & 5 & 6 & 8 & 15 & 18 & 18 & 3 & 6 & 5 & 7 & 14 & 15 \\
\hline Medium & $0.40-0.55$ & 3 & 7 & 3 & 17 & 17 & 17 & 12 & 6 & 7 & 3 & 2 & 2 & 14 & 12 & 12 \\
\hline Inferior & $0.00-0.40$ & 18 & 14 & 14 & 8 & 7 & 5 & 1 & 3 & 3 & 24 & 1 & 0 & 10 & 2 & 1 \\
\hline
\end{tabular}

a $\mathrm{A}, \mathrm{B}$, and $\mathrm{C}$ represent 6 th, 7 th, and 8th NFI, respectively.

those in another cluster. CA can provide the references for classifying the management of forest.

In this study, a hierarchical agglomeration algorithm for clustering was applied. The clustering method of between-group linkage and squared Euclidean distance were used to compute the distance among different provinces based on the normalized values during 8th NFI (Section 2.2). All the factors relating to FRQ were considered for $C A$, and these calculations were performed using Origin 2015 software (OriginLab Corp., USA).

\section{Results}

\subsection{Dynamic change in the four criteria and FRQ}

\subsubsection{Forest quantity}

In terms of the forest quantity criterion, there was only one factor (Table 1). From the 6th to 8th NFI, forest coverage rates of the 31 provinces in China increased by varying degrees (Fig. 1a). Moreover, the number of provinces scoring at inferior level decreased by 4 , while the number scoring at an excellent level increased by 3-4 (Table 4). As a whole, nearly half of the provinces scored at an inferior level in the recent 8th NFI. During the three NFIs, the forest coverage rates for Fujian, Jiangxi and Zhejiang Provinces were the highest, while those for Xinjiang and Qinghai Provinces were the lowest (Fig. 1a). In general, the implementation of the three ecological projects had effectively improved the forest quantity level of all the 31 provinces in China. From the 6th to 8th NFI, the improvement in forest quantity scores was greatest for Chongqing, Guangxi, and Beijing Provinces, with values of 0.2574, 0.2397, and 0.2322, respectively, while Tibet, Qinghai, and Xinjiang Provinces were found to be the least improved, with values of $0.0108,0.0195$, and 0.0213 , respectively (Fig. 1a).

\subsubsection{Forest productivity}

Forest productivity factors included forestry land utilization rate, stock volume per unit area, stock quality, and stock volume increment (Table 3). The ranges of forest productivity scores during the three NFIs were $0.2402-0.7087,0.2530-0.8170$, and $0.2530-$ 0.8232 , respectively (Fig. 1b). In terms of grades, few differences were found among the three NFIs (Table 4). However, it is important to note that more than a third of these provinces were scored at a medium or inferior level (Table 4). From the 6th to 8th NFI, the forest productivity scores of Jilin, Shanghai, Guangdong, Chongqing, Shaanxi, and Gansu increased at first and then decreased, while the score for Hunan decreased at first and then increased, and that for the other provinces increased gradually (Fig. 1b). In general, the forest productivity for the 30 provinces increased by varying degrees, whereas only one province was found to have decreased slightly in productivity. The forest productivity scores for Tibet during the three NFIs were greater than those of the other provinces, indicating that optimal forest productivity occurred among the 31 provinces, whereas lowest level of productivity occurred in Ningxia.

\subsubsection{Forest structure}

Forest structure factors included stand origin structure, forest category structure, tree species structure, age group structure, and canopy structure (Table 3). From the 6th to 8th NFI, the forest structure scores of the 31 provinces presented different change trends. The forest structure scores for 15 provinces increased by varying degrees, while those for the other 16 provinces decreased (Fig. 1c). In terms of grades, few differences were found between the number of provinces scoring at excellent and inferior levels among the three NFIs, but the number of provinces scoring at a good level increased by four (Table 4). The forest structure scores for Tianjin, Shanghai, Jiangsu and Shandong during the three NFIs 


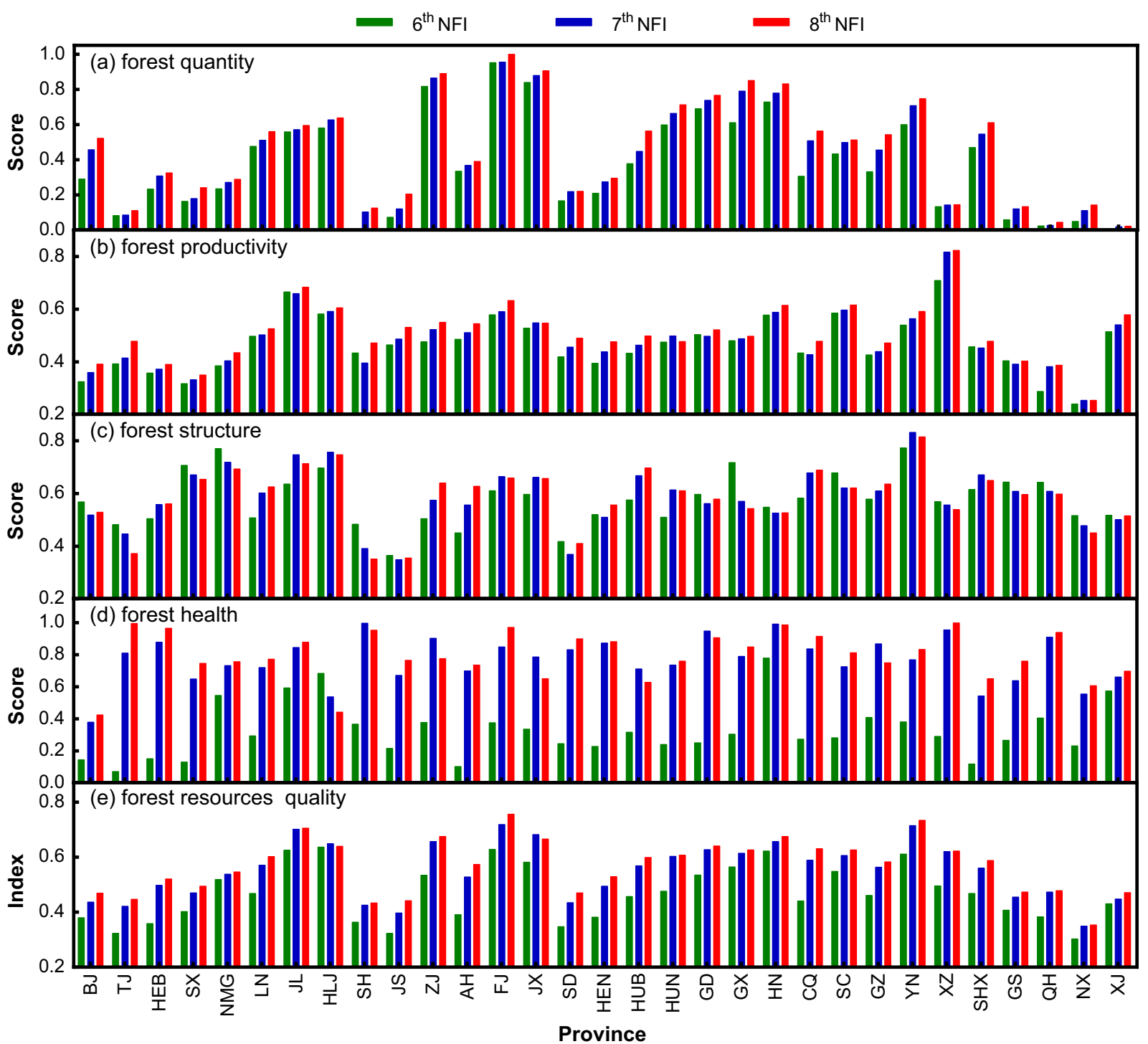

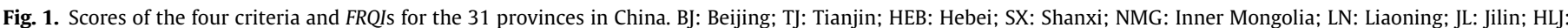

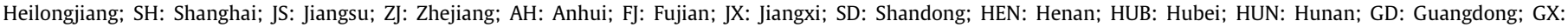
Guangxi; HN: Hainan; CQ: Chongqing; SC: Sichuan; GZ: Guizhou; YN: Yunnan; XZ: Tibet; SHX: Shaanxi; GS: Gansu; QH: Qinghai; NX: Ningxia; XJ: Xinjiang.

were the lowest, mainly because the proportion of natural forest for these provinces was much lower than that for the other provinces, leading to low normalized values (scores) for those factors. Of the 31 provinces in China, Yunnan, Shanxi, Inner Mongolia, Jilin, and Heilongjiang exhibited the most optimal forest structure.

\subsubsection{Forest health}

Forest health factors included forest viability and forest calamity (Table 3). The forest health scores fluctuated considerably during the three NFIs (Fig. 1d). Compared with the 6th NFI, forest health scores of 30 provinces during the 7 th and 8th NFIs increased significantly, while the score of only one province decreased (Fig. 1d). The ranges of forest health scores during the three NFIs were $0.0712-0.7778,0.3786-0.9957$, and $0.4244-0.9972$, respectively. For the two most recent NFIs, the forest health scores of 8 provinces decreased by varying degrees, indicating that forest health of these provinces has deteriorated, mainly because the percentages of forest with high viability for these provinces decreased sharply. In terms of classification, most provinces (90\%) scored an excellent or good level during the 7th and 8th NFIs.

\subsubsection{Forest resources quality}

The ranges of $F R Q I$ values for the 31 provinces during the three NFIs were 0.3031-0.6366, 0.3499-0.7186, and 0.3534-0.7555, respectively. From the 6th to 8 th NFI, the FRQIs of all 31 provinces in China increased by different degrees (Fig. 1e). In terms of classification, only 7 provinces in China showed a good level during the 6th NFI; most provinces showed a medium or inferior level. During the 8th NFI, 3 provinces (Jilin, Fujian and Yunnan) scored at an excellent level, 15 provinces scored at a good level, 12 provinces scoring at a medium level, and only one province (Ningxia) scored at an inferior level (Table 4). For the country as a whole, the FRQI values during the three NFIs were 0.4667, 0.5506, and 0.5701, respectively, which indicated that the FRQ for China had improved significantly at the national level.

\subsection{Comparison among different clusters}

According to the dendrogram resulting from the application of CA (Fig. 2), forest resources in the 31 provinces could be grouped into four clusters (Fig. 3). The mean scores and FRQI for each cluster were calculated and presented in Fig. 4. Next, the current states 
relating to each cluster were analyzed, and some management measures were proposed.

Cluster I included the following 17 provinces: Beijing, Liaoning, Jilin, Heilongjiang, Zhejiang, Anhui, Fujian, Jiangxi, Hubei, Hunan, Guangdong, Guangxi, Chongqing, Sichuan, Guizhou, Yunnan, and Shaanxi (Fig. 3). In terms of geographical position and climate, these provinces are located in northeast China and in the south side area of Qinling-Huaihe Line. The main characteristics of this cluster were that the mean scores for the forest coverage rate and age group structure were the highest among the four clusters, while the other 10 factors scored at a middle level (Fig. 4). Furthermore, the mean FRQI of this cluster was 0.6305 , which was much higher than the FRQI at the national level (0.5701). In general, the FRQ of the 17 provinces in this cluster was relatively good.

Cluster II included the seven provinces of Tianjin, Hebei, Shanghai, Jiangsu, Shandong, Henan, and Hainan (Fig. 3). Its mean FRQI (0.5022) was lower than that at the national level (0.5701). Furthermore, the mean scores for stock volume per unit area $(0.1065)$, stock quality $(0.7231)$, stand origin structure $(0.1732)$, and tree species structure $(0.3142)$ for Cluster II were the lowest of all four clusters (Fig. 4). This state indicated that forest productivity and forest structure were the key factors limiting the FRQ of the seven provinces, and that various measures (e.g. intermediate cutting) need to be implemented in future forest management to improve this situation.

Cluster III included the six provinces of Shanxi, Inner Mongolia, Gansu, Qinghai, Ningxia, and Xinjiang (Fig. 3). These provinces are located in northwest and north China, and all of them belong to arid or semiarid areas. Warm temperate grasslands and deserts are the two main ecosystem types in these provinces. The main characteristics of this cluster were that the mean scores for forest coverage rate, and forestry land utilization rate were much lower than those of the other clusters, and these factors limited the FRQ for this cluster. To a certain extent, these projects improved the FRQ of these provinces (Fig. 1a): both forest quantity and forest health improved by different degrees (Fig. $1 \mathrm{a}$ and d). However, forest structure and forest productivity presented a decreasing or changeless trend (Fig. 1b and c). This may have been because the artificial afforestation was mainly created by pure forest, and forest growth is periodic, resulting in, for example, an unreasonable forest category structure and tree species structure, and smaller stock volume per unit area. The mean FRQI (0.4694) of this cluster was much lower than that at the national level (0.5701) (Fig. 4), indicating an urgent need for FRQ of these provinces to be improved.

Cluster IV included only one province, Tibet. The results for this province were in striking contrast to those for the other 30 provinces. The mean scores for stock volume per unit area, stock quality, stand origin structure, tree species structure, forest viability, and forest calamity were the highest for all four clusters, while those for forest coverage rate, forest category structure, and age group structure were the lowest (Fig. 4). The mean altitude of Tibet is the highest in China, and its forest is mainly distributed in the southeast of the province. The other parts of Tibet are mainly covered with alpine meadow and grassland ecosystems, resulting in a low forest coverage rate. The stand origin of forests in Tibet comprises $99.43 \%$ natural forest. Moreover, its forest ecosystem structure is very stable and better able to resist natural disasters, such as forest diseases and insect pests. In terms of age group structure, the percentage of near-mature, mature, and over-mature forest was $82.64 \%$, much higher than the ideal proportion of $33.33 \%$; and this has led to a high stock volume per unit area of $266.59 \mathrm{~m}^{3} \mathrm{hm}^{-2}$. Because of the unique geographical environment in Tibet, the development and degree of utilization of its forest has been extremely low, which has led to a low percentage of commercial forest.

Few differences were found in the mean scores for stock volume increment, and forest calamity among the four clusters, and their ranges were $0.8236-0.8714$, and $0.9120-1.0000$, which indicated that the two factors were in a very good state. However, the mean scores for canopy structure for the four clusters were lower than 0.02 , indicating that this was the key factor limiting the FRQ of all the provinces. Therefore, measures should be implemented in future forest management to improve the condition of canopy structure.

\section{Discussion}

In this study, FRQ at the provincial and national levels was assessed and analyzed successfully using AHP and CA. Twelve factors including forest quantity, forest productivity, forest structure, and forest health were selected as criteria, and their scores and weights were calculated using normalization techniques and AHP approach. Next, FRQI values for the 31 provinces during the 6th, 7th, and 8th NFI were calculated using a linear additive combination model. Based on CA, the similar problems existing in the same clusters were analyzed, and some relevant management measures were proposed.

Several normalization methods are commonly used in the assessment of land suitability and forest quality to convert the different measurement units of the performance ratings into a comparable unit, such as fuzzy set modeling (Zhang et al., 2011; Zhang et al., 2015), expert scoring method (Guo et al., 2010; Wang and Bao, 2011; Akinci et al., 2013), and linear scale transformation (e.g. Max-Min Method, Max Method, and Sum Method) (Wang et al., 2013; Mo et al., 2015). In general, each normalization method has its own advantages and disadvantages. In this study, we used the Max-Min Method to normalize the recalculated data. There are three main reasons for using this method. The first is that the current study on FRQ assessment is limited, and we cannot obtain the upper and lower limit values for each factor that could

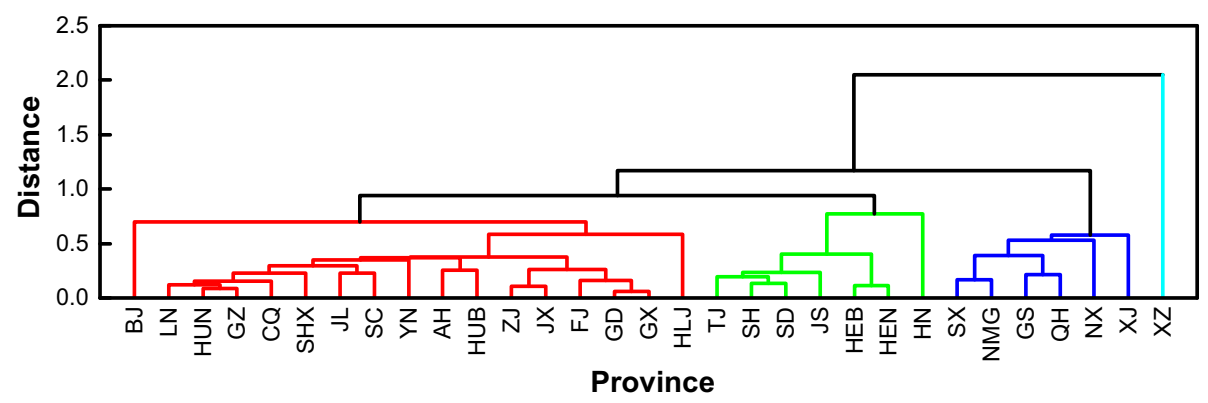

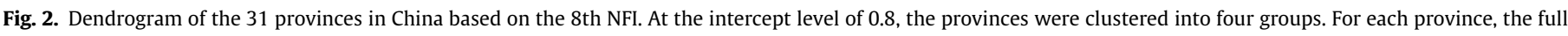
name is listed in the legend of Fig. 1. 


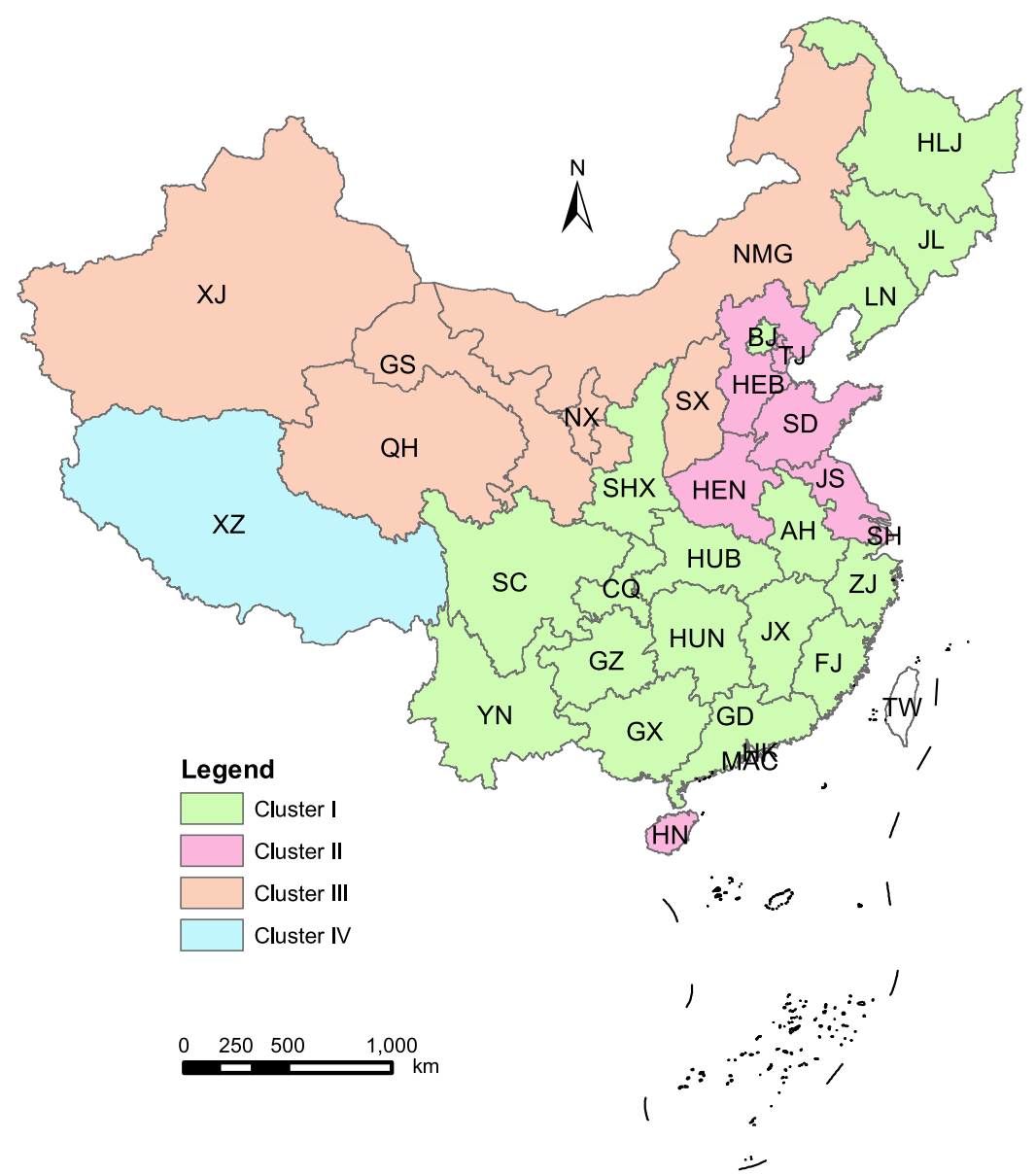

Fig. 3. Classifications and locations of the 31 provinces in China. For each province, the full name is listed in the legend of Fig. 1.

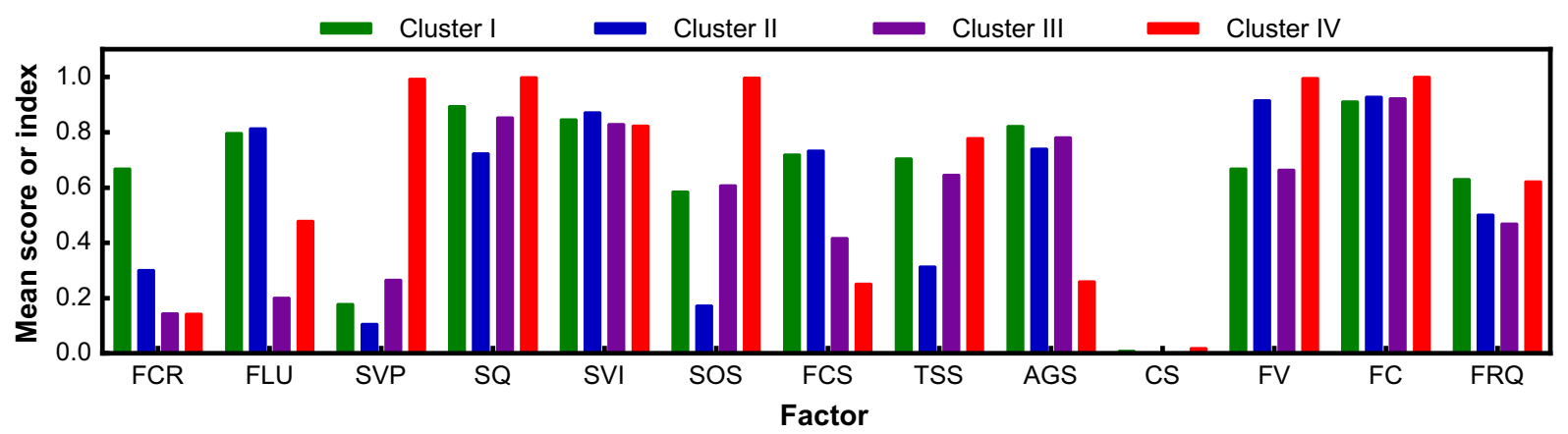

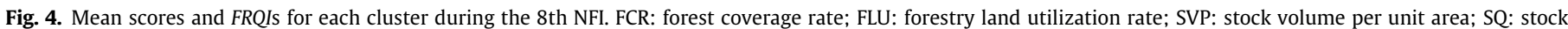

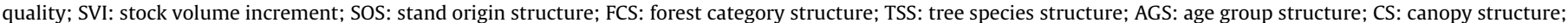
FV: forest viability; FC: forest calamity; FRQ: forest resources quality.

be used in a fuzzy set model. The second reason is that expert scoring method requires the involvement of more scientists and relevant personnel to divide and determine the upper and lower limit values for each grade; and the scoring process should be based on the intrinsic attributes of long-term observation and research on forests. At present, this seems unlikely. The third reason is that this study focused on the relative changes in the FRQ for each province during the three NFIs, the normalization methods used were capable of meeting the goals of this study and are easy to use. These normalization methods have the advantage that the scale measurement is precisely between 0 and 1 for each factor (Celen, 2014). In addition, the weights of the factors lie between
0 and 1, so the FRQI values also lie between 0 and 1, which helps to divide the grades of FRQ.

In the MCDM process, one of the challenges is to determine the weight of all factors (Zhang et al., 2015). Using AHP, we established a model to assess FRQ at the provincial level. In the AHP model, several factors (12 in this study) need to be considered simultaneously, but they influence FRQ unequally. Various methods for determining the weights of these factors have been explored, such as the Matter-Element Model (Chen et al., 2011; Wu and Zhao, 2011) and factor analysis (Mo et al., 2015). Nevertheless, these methods have some drawbacks in identifying the perfect weights. Firstly, the inconsistencies cannot be measured and controlled in 
the presence of conflicting criteria. Secondly, these methods are more suitable for assessing FRQ on a small scale (e.g. stand and subcompartment), in that they demand there should exist good correlations among factors (Zhang et al., 2015). In this study, the weights of 12 factors were well assigned and consistency ratios were calculated using AHP approach. AHP is a useful systematic tool for handling MCDM processes (Yang et al., 2008; Samari et al., 2012). Compared with the methods mentioned above, AHP is a very effective and powerful method to determine the weights. The weights of forest coverage rate, stock volume per unit area, and stand origin structure were $0.1810,0.1447$, and 0.1174 , respectively, indicating that these factors had great impact on the FRQ; these results were consistent with those of previous studies (Dang et al., 2008; Wu, 2010; Zhang et al., 2011). However, the weights for tree species structure $(0.0392)$ and stock quality (0.0356) and canopy structure (0.0288) were the lowest of all the factors. The differences among assessment factors reflect their relative importance on FRQ.

The FRQ across China significantly changed from the 6th to 8th NFI. These changes derived from both internal and external factors. The internal factor is that forest has its own growth laws and change trends, e.g. tree growth leads to an increase in the total stock volume in a fixed stand. The external factors are that the management and adjustment by humans causes forest resources to change, e.g. artificial tending increases the stock volume per unit area in a stand. Because the forest ecosystem has stability and protracted nature, so the change in forest resources is mainly caused by external factors. Following the implementation of the three ecological projects mentioned above, the FRQ of the 31 province were found to have changed significantly from the 6th to 8th NFI. Among the four criteria for FRQ only the score for forest quantity increased by different degrees for all provinces. The reason for this was that substantial artificial afforestation increased the total forest area, which then increased the forest coverage rate for each province. However, artificial afforestation had various negative effects on forest productivity, structure and health. As mentioned above, the increase in artificial forest resulted in a decline in the proportion of natural forest and an increase in the proportion of young- and middle-aged forest and forest calamity. Thus, these factors would alter forest productivity, structure, and health as a consequence.

\section{Conclusion}

Based on the NFI data set, the FRQ at the provincial level was assessed successfully using AHP and CA. The results demonstrated that the ranges of FRQIs for the 31 provinces during 1999-2003, 2004-2008, and 2009-2013 were 0.3031-0.6366, 0.3499-0.7186, and $0.3534-0.7555$, respectively. During the 8th NFI, the numbers of provinces scoring at excellent, good, medium and inferior level were $3,15,12$, and 1 , respectively. In general, the implementation of ecological projects had significantly improved the FRQ at provincial and national levels. Chinese forest resources during the 8th NFI could be grouped into four clusters according to the provincial administrative region. Each cluster had its own advantages and disadvantages, and measures need to be implemented in the future management of forest resources to improve the situation in each province. The results can provide theoretical and technical supports for forest management in China.

\section{Acknowledgements}

This study was financially supported by the foundation of the Action Plan for the Development of Western China of Chinese Academy of Sciences (Grant No. KZCX2-XB3-08-03). We thank the State Forestry Administration of the People's Republic of China and the Chinese Forestry Science Data Center (CFSDC) for providing the data used in the study.

\section{References}

Achard, F., Eva, H.D., Stibig, H.J., Mayaux, P., Gallego, J., Richards, T., Malingreau, J.P., 2002. Determination of deforestation rates of the world's humid tropical forests. Science 297 (5583), 999-1002. http://dx.doi.org/10.1126/science. 1070656

Akinci, H., Ozalp, A.Y., Turgut, B., 2013. Agricultural land use suitability analysis using GIS and AHP technique. Comput. Electron. Agric. 97, 71-82. http://dx.doi. org/10.1016/j.compag.2013.07.006.

Al-Oqla, F.M., Sapuan, S.M., Ishak, M.R., Nuraini, A.A., 2015. Predicting the potential of agro waste fibers for sustainable automotive industry using a decision making model. Comput. Electron. Agric. 113, 116-127. http://dx.doi.org/ 10.1016/j.compag.2015.01.011.

Amsallem, I., Loyche Wilkie, M., Kone, P., Ngandji, M., 2003. Sustainable management of tropical forests in central Africa. In: Search of Excellence. FAO Forestry Paper. Food and Agriculture Organization, Rome.

Bishop, C.M., 2006. Pattern Recognition and Machine Learning (Information Science and Statistics). Springer, Singapore.

Celen, A., 2014. Comparative analysis of normalization procedures in TOPSIS method: with an application to Turkish deposit banking market. Informatica 24 (2), 185-208.

Cha, D.S., 2015. Classification of forest welfare service using the cluster analysis: case study in Gangwon Province. J. Assn. Korean Photo-Geogr. 25 (1), 115-124 (in Korean with English abstract).

Chang Y, Zhu, Z L, Bu, R.C. Li, Y. H., Hu, Y.M., 2015. Environmental controls on the characteristics of mean number of forest fires and mean forest area burned (1987-2007) in China. Forest Ecol. Manag. 356 (SI), 13-21. http://dx.doi.org/ 10.1016/j.foreco.2015.07.012.

Chen, J.H., Zhu, Z.F., Gong, G.T., Wang, S.Y., Wu, X.X., He, Z.W., 2011. Quality evaluation of protection forest based on grid and matter element model. Bull Soil Water Conserv. 31 (4), 116-121 (in Chinese with English abstract).

Costanza, R., dArge, R., deGroot, R., Farber, S., Grasso, M., Hannon, B., Limburg, K. Naeem, S., Oneill, R.V., Paruelo, J., Raskin, R.G., Sutton, P., vandenBelt, M., 1997. The value of the world's ecosystem services and natural capital. Nature 387 (6630), 253-260. http://dx.doi.org/10.1038/387253a0.

Dang, P.X., Hou, X.W., Hui, G.Y., Zhao, Z.H., 2008. Evaluation indicator system and evaluation method of regional forest resource quality. Forest Res. 21 (1), 84-90 (in Chinese with English abstract).

Dudley, N., Schlaepfer, R., Jackson, W., Jeanrenaud, J.P., Stolton, S., 2006. Forest Quality: Assessing Forests at a Landscape Scale. Earthscan Publications Ltd., London.

Food and Agriculture Organization of the United Nations (FAO), 2005. Global Forest Resources Assessment 2005-Country Report China. Food and Agriculture Organization, Rome.

Garcia, J.L., Alvarado, A., Blanco, J., Jimenez, E., Maldonado, A.A., Cortes, G., 2014 Multi-attribute evaluation and selection of sites for agricultural product warehouses based on an analytic hierarchy process. Comput. Electron. Agric. 100, 60-69. http://dx.doi.org/10.1016/j.compag.2013.10.009.

Gong, L., Zhang, Z.D., Xu, C.Y., 2015. Developing a quality assessment index system for scenic forest management: a case study from Xishan Mountain, suburban Beijing. Forests 6 (1), 225-243. http://dx.doi.org/10.3390/f6010225.

Guo, N., Xing, S.H., Ji, W.Y., Cui, G.F., Ze, L.G., Wang, M., Xue, Q., Jiang, X.M., 2010. A method for forest resources quality evaluation and its application in Miyaluo forest regions, Western Sichuan. Acta Ecol. Sin. (Chin. Ed.) 30 (14), 3784-3791 (in Chinese with English abstract).

Haefele, M., Kramer, R.A., Holmes, T., 1992. Estimating the Total Value of Forest Quality in High-Elevation Spruce-Fire Forests. General Technical Report SE U.S Department of Agriculture Forest Service Southeastern Forest Experiment Station.

Lee, S., Kim, W. Kim, Y.M., Lee, H.Y., Oh, KJ. 2014. The prioritization and verification of IT emerging technologies using an analytic hierarchy process and cluster analysis. Technol. Forecast. Soc. 87, 292-304. http://dx.doi.org/10.1016/j. techfore.2013.12.029.

Li, W.H., Li, F. 1996. Research of Forest Resources in China. China Forestry Publishing House, Beijing (in Chinese).

Li, T.Y., Chen, X., Deng, J., Chen, K., Sun, W.H., Zheng, Y., 2015. Zoning of forest fire risk grade of Fujian province based on hierachical clustering analysis. J. Fujian For. Sci. Tech. 42 (4), 148-152. http://dx.doi.org/10.3969/j.issn.10058141.2015.12.012 (in Chinese with English abstract).

Ma, L., Feng, Z.M., Feng, Z.K., Gao, X., 2015. Cluster analysis and recommendations on management measures of dominant factors of forest small class in Yellow Mud River. J. Cent. S. Univ. For. Tech. 35 (12), 64-68. http://dx.doi.org/10.14067/ j.cnki.1673-923x.2015.12.012 (in Chinese with English abstract)

Manly, B.F.J., 1994. Multivariate Statistical Methods-A Primer, second ed. Chapman and Hall, London, pp. 129-133.

McKenna, J.E., 2003. An enhanced cluster analysis program with bootstrap significance testing for ecological community analysis. Environ. Model. Softw. 18 (3), 205-220. http://dx.doi.org/10.1016/s1364-8152(02)00094-4.

Mo, K., Zhao, T.Z., Lan, H.Y., Li, W., 2015. Quality assessment at subcompartment level of forests used for timber production based on factor analysis: a case study 
in Jiangle national forest farm. Fujian Province. J. Beijing For. Univ. 37 (1), 4854. http://dx.doi.org/10.13332/j.cnki.jbfu.2015.01.007 (in Chinese with English abstract).

Nunez, D., Nahuelhual, L., Oyarzun, C., 2006. Forests and water: the value of native temperate forests in supplying water for human consumption. Ecol. Econ. 58 (3), 606-616. http://dx.doi.org/10.1016/j.ecolecon.2005.08.010.

Orozco, C.V., Tonini, M., Conedera, M., Kanveski, M., 2012. Cluster recognition in spatial-temporal sequences: the case of forest fires. Geoinformatica 16 (4), 653673. http://dx.doi.org/10.1007/s10707-012-0161-z.

Petcharat, S., Chungpaibulpatana, S., Rakkwamsuk, P., 2012. Assessment of potential energy saving using cluster analysis: a case study of lighting systems in buildings. Energy Build. 52, 145-152. http://dx.doi.org/10.1016/j. enbuild.2012.06.006.

Research Group of Forestry Sustainable Development in China (RGFSD), 2003 Conspectus of Research on Forestry Sustainable Development in China. China Forestry Publishing House, Beijing (in Chinese).

Riedler, B., Pernkopf, L., Strasser, T., Lang, S., Smith, G., 2015. A composite indicator for assessing habitat quality of riparian forests derived from Earth observation data. Int. J. Appl. Earth Obs. 37, 114-123. http://dx.doi.org/10.1016/ j.jag.2014.09.006

Saaty, T.L., 1980. The Analytic Hierarchy Process: Planning, Priority Setting, Resource Allocation. McGraw-Hill International, New York, NY, USA

Saaty, T.L., 1994. Fundamentals of Decision Making and Priority Theory with the AHP. RWS Publications, Pittsburgh, PA, USA.

Saaty, T.L., 2008. Decision making with the analytic hierarchy process. Int. J. Serv. Sci 1 (1), 83-98. http://dx.doi.org/10.1504/IJSSci.2008.01759.

Samari, D., Azadi, H., Zarafshani, K., Hosseininia, G., Witlox, F., 2012. Determining appropriate forestry extension model: application of AHP in the Zagros area. Iran. Forest Policy Econ. 15, 91-97. http://dx.doi.org/10.1016/ j.forpol.2011.10.006

Shi, C.N., Wang, L.Q., 2007. A review of researches on evaluation system of forest resources quality in china. World For. Res. 20 (2), 68-72 (in Chinese with English abstract).

State Forestry Administration of the People's Republic of China (SFA), 2012. Forest Category Classification (LY/T 2012-2012). China Standards Press, Beijing (in Chinese).
State Forestry Administration of the People's Republic of China (SFA), 2008. Specifications for Assessment of Forest Ecosystem Services in China (LY/T 17212008). China Standards Press, Beijing (in Chinese).

Wang, N.J., Bao, Y.Q., 2011. Modeling forest quality at stand level: a case study of loess plateau in China. Forest Policy Econ. 13 (6), 488-495. http://dx.doi.org/ 10.1016/j.forpol.2011.05.012

Wang, X.R., Liu, X.Q., Tang, W.P., Pang, H.D., 2013. Evaluation on stand quality of water conservation forest in Longkou Forest Farm on Danjiangkou reservoir area. J. Nanjing For. Univ. (Nat. Sci. Ed.) 37 (4), 63-68. http://dx.doi.org/10.3969/ j.issn.1000-2006.2013.04.012 (in Chinese with English abstract).

Wu, G.J., Zhao, T.Z., 2011. Evaluation of forest resource quality based on matterelement model. J. Southern Argic. 42 (1), 109-113 (in Chinese with English abstract).

Wu, G.X., 2010. The study on indicator system and evaluation method of forest resources quality at county-level Doctoral thesis. Beijing Forestry University, Beijing (in Chinese with English abstract).

Yang, F., Zeng, G.M., Du, C.Y., Tang, L., Zhou, J.F., Li, Z.W., 2008. Spatial analyzing system for urban land-use management based on GIS and multi-criteria assessment modeling. Prog. Nat. Sci. 18 (10), 1279-1284. http://dx.doi.org/ 10.1016/j.pnsc.2008.05.007.

Yang, L., Zhang, D.H., Wang, J.L., Li, Y.Y., 2015. Study on country forest ecological security evaluation in China: based on empirical data of fifteen pilot coanties in five provinces. Ecol. Econ. 31 (12), 120-124 (in Chinese with English abstract).

Zhang, H.R., He, P., Lang, P.M., 2011. Comprehensive evaluation of forest resource in Yanqing county based on AHP and fuzzy methods. J. Northwest For. Univ. 26 (5), 179-184 (in Chinese with English abstract).

Zhang, J.Q., Su, Y.R., Wu, J.S., Liang, H.B., 2015. GIS based land suitability assessment for tobacco production using AHP and fuzzy set in Shandong province of China. Comput. Electron. Agric. 114, 202-211. http://dx.doi.org/10.1016/ j.compag.2015.04.004.

Zhao, T.Z., Ke, S.F., Gao, L., Wen, Y.L., 2004. The impact of forest calamity on China's forestry economic growth. J. Beijing For. Univ. (Soc. Sci. Ed.) 3 (2), 37-40. http:// dx.doi.org/10.13931/j .cnki .bjfuss.2004.02.009 (in Chinese with English abstract). 